\title{
Three Questions To Guide Study and Practice in the Information Systems Field
}

\author{
JuanQiong Gou \\ Beijing Jiaotong University, China \\ Arthur Tatnall \\ Victoria University, Australia
}

\begin{abstract}
Gaining an understanding of Information Systems and improving IS education has become a serious issue for the IS discipline. Prior to undertaking Management Information Systems (MIS) in an MBA course, students sometimes cannot clearly explain exactly what information systems are and what they should do in practice. This paper begins by considering the various influences on the MIS curriculum and some of the conventional approaches to curriculum design, selection and organisation of teaching materials. It then offers an alternative approach by presenting a three question framework for understanding and explaining the IS field. From this basis the paper argues that these three questions can be used to guide the study, teaching and practice of MIS.
\end{abstract}

\section{Keywords}

Information and Communication Technologies (ICT), Information Systems (IS), management information systems (MIS), IS discipline, IS curriculum, IS practice.

\section{Introduction}

As Information Systems (IS) become ever more important in the functioning and development of organisations, society and the economy, one would expect the IS discipline and its graduates to be highly valued, but in some instances this is not always the case. Students of Management Information Systems (MIS) and even some teachers and researchers in IS sometimes cannot clearly explain to students exactly what information systems are and what they should do in practice. In this paper we examine the nature of the IS discipline in an attempt to provide a clear and easy way to depict it, especially to MBA students undertaking an MIS subject.

The Information Systems field grew from computer data processing in the 1950s and, with maturity, the distinct domain of IS reveals itself in the interaction and permanent interplay between Information and Communication Technologies (ICT) and the social/organisational context. Aspects of the design and use of ICT can be found in the disciplines of Computer Science, Computer Systems Engineering and Information Systems, but this paper focuses on those aspects of ICT involving Information Systems. Lee (2001) emphasises this as follows: "research in IS examines more than just the technological system, or just the social system, or even the two side by side ... it investigates the phenomena that

Copyright (C) 2006 Victoria University. This document has been published as part of the Journal of Business Systems, Governance and Ethics in both online and print formats. Educational and nonprofit institutions are granted a nonexclusive licence to utilise this document in whole or in part for personal or classroom use without fee, provided that correct attribution and citation are made and this copyright statement is reproduced. Any other usage is prohibited without the express permission of the publisher.

:iii). 


\section{The IS Curriculum Development Process}

Information systems curricula are under constant pressure to change as is well known to all those involved in their delivery. Many of the studies on curriculum development and change reported in the literature are based on research, development and dissemination models (Havelock 1971). Relying on logical and rational decisions, change models of this type depend on the use of convincing arguments based on programs of research.

Research $\rightarrow$ Development $\rightarrow$ Production $\rightarrow$ Dissemination $\rightarrow$ Adoption

Figure 1: Research-Development-Dissemination Model

Problem solving models (Nordvall 1982) represent another approach to conceptualising curriculum change in which this is seen as due to perceived educational need. Also a quite rational approach they involve searching for alternative solutions, often by looking at what colleagues with similar interests are doing but sometimes by other forms of research, in an attempt to find a solution to the educational problem.

A related approach is to consider that many curriculum statements result from the conscious or unconscious copying of 'authoritative' existing statements, rather than from any new thought (Clements, Grimison and Ellerton 1989). Curriculum documents from groups like IFIP, ACM, IEEE and IRMA have, in many cases, tended to act as 'authoritative' statements in this way (Longenecker, Feinstein, Couger, Davis and Gorgone 1994; Davis, Gorgone, Cougar, Feinstein and Longnecker 1997).

Writing in relation to Master's level curricula in Management Information Systems in the United States, Sandman (1993) offers seven principal environmental forces which he contends shape this curriculum and trigger its reassessment.

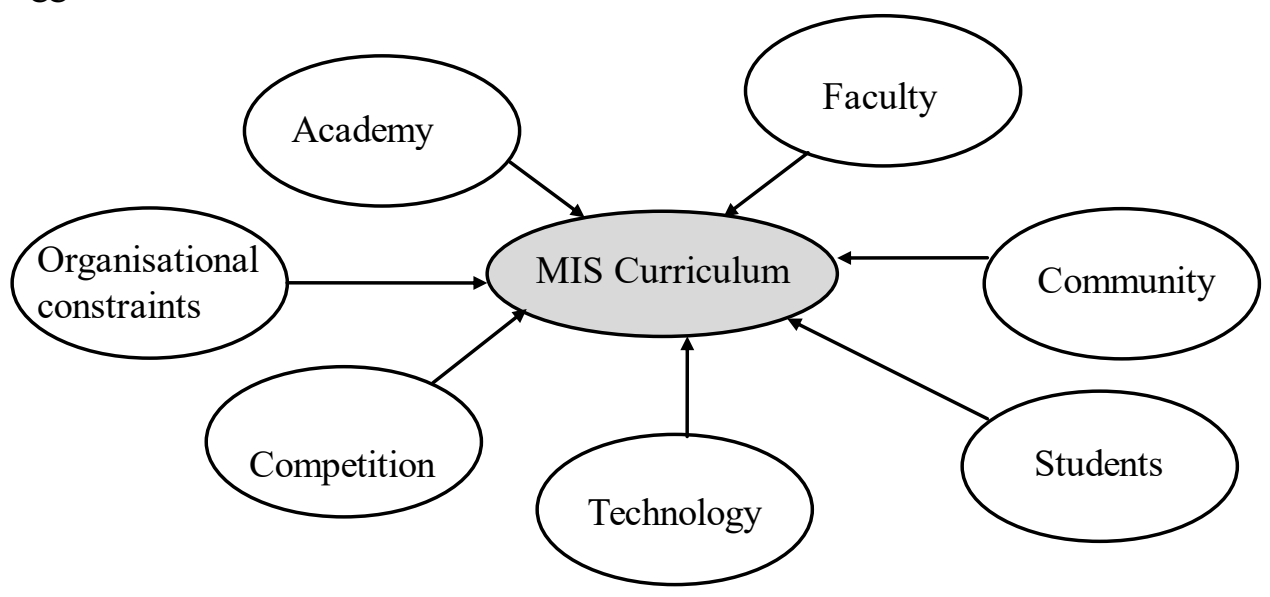

Figure 2: Influences on MIS curriculum (- adapted from Sandman (1993))

The strongest of the seven forces Sandman postulates is that of the 'academy', a term he uses to mean the requisite body of knowledge prescribed by one of the professional associations. For some time professional bodies around the world, such as the Australian Computer Society (ACS), have published documents setting out what they regard as the Body of Knowledge required of a computer professional (ACS 1997). A core Body of Knowledge is expressed in a form intended to assist university computing departments with the development of their curricula.

Obviously the faculty of academics who teach the program has an influence and Sandman considers that the background and experience of these academics can be a limiting factor. IS graduates undertake masters courses primarily in order to get better jobs, he asserts, and so the views of the local industrial community are an important force to take into account in developing a curriculum. Student background is another constraining factor. In common with a number of writers on IS curriculum (Nunamaker 1981; Longenecker, Feinstein et al. 1994; Cougar, Davis, Gorgone, Feinstein and Longenecker 1995), 
Sandman argues that this is a technology-driven field and that emergent technologies are an important force in this dynamic area. Competition for students is a force for curriculum change as courses adapt to capture the ever elusive extra student. Finally, organisational constraints are also important forces for change. These range from internal departmental power struggles to shortages of funds and equipment (Sandman 1993).

A reading of a number of other papers on IS curriculum suggests that two issues currently stand out as particularly significant: how courses can be kept up to date, and the balance between technical, managerial and human skills required of students. Each of these issues relates to students later finding jobs in the computer industry. Model curriculum IS'97 (Davis, Gorgone et al. 1997) sees the academic field of Information Systems as encompassing two broad areas:

- An Information Systems function consisting of the acquisition, deployment and management of information technology resources and services.

- A Systems Development function involving development and evolution of infrastructure and systems for information use in organisational processes.

It seems clear to us that development of information systems curriculum is a much less straightforward and much more complex process that simple research-development-dissemination or problem solving models suggest. Changes in technology certainly play an important part, but as seem in Sandman's (1993) model, so do many other factors. IS curriculum development cannot be thought of as simply technology-driven but really must be considered as a socio-technical process.

\section{Three Questions to Guide Understanding the IS Field}

Another approach to the definition of the IS field and to deciding what an information systems curriculum should contain is based on asking three broad questions. After listening to the questions of students and enterprise managers, and teaching and researching in information systems for many years, we propose these three questions to guide understanding of the IS field, help students understand and study IS, and help managers make best use of IS as they deploy ICT in their organisations. The three questions focus on a combination of IS and management, from different views and levels, to guide thinking about the IS discipline. The questions are:

- Why are information systems so important for organisations today?

- How can you customise ICT to meet challenges to organisations?

- How do you change organisations to get best advantage from ICT?

By continuous refinement, the 3 questions have been proved meaningful when explaining the IS discipline, especially to those who know little of IS, useful when organising IS teaching materials and valuable when guiding practice in the IS field. This paper presents some examples of using the three questions to analyse the IS discipline, organise MIS textbook materials, and analyse some topics in IS practice.

\section{Using the Three Questions in an Explanation of IS Itself}

For many people the term Management Information Systems just means some form of software, but it is more useful to consider it as having the following three features:

1. The ability to support management with information

2. It makes use of Information and Communication Technologies (ICT)

3. It is a system.

These three features can then be used to explain IS more clearly. The first feature represents the purpose of information systems, which makes it different to other kinds of software. In the past the main function of an Information System was processing information to support management. This included transactions, daily management, and decision making. Now, with new technologies and new application 
areas, information systems are expected to cover all fields in enterprise and society, including Ecommerce and related applications. The second feature emphasises the tools of IS. Without information and communication technologies humans are still able to process information and undertake management tasks, but ICT provides such a powerful approach that we should understand and explore its advantages and be able to undertake development to enhance these more and more. The third feature is the core of the socio-technical nature of information systems. No matter how we analyse the components of the system these must include management, organisation and technology, and all components in the system should collaborate.

These features also correspond with the three questions proposed in understanding the IS field. The first feature is just another way of asking the first question as each enterprise has its own situations and aims. The second feature allows the customisation of an MIS as the means to get it to satisfy client needs. The third feature is not only related to the third question it is also a combination of the last two questions.

\section{Using the Three Questions as an Explanation of the IS Discipline}

Information Systems is multidisciplinary: it is a combination of management science, computer science, and system science (Khazanchi and Munkvold 2000; Elliot 2002). Students of IS will study a lot in common from these three sciences, each of which is itself multi-faceted. Research and practice in IS will meet with various questions related to the other disciplines, some of which seem to have no relation to each other and which make the IS discipline seem unclear.

Ingwersen (1996) has defined IS as "the study of the effective use of information and the potential impact of software systems and enabling information technologies on the human, organisational, and social world", he emphases that "... the principle role of IS is to arrange information technology. We deal with commercial architecture, with system design and analysis, and with managerial and organisational aspects of information technology. Although we do create some software technology, most of what we do is to react to it."

In the application of IS in business the three questions emphasise the relation between technology and commercial practice. The first question reflects features of IS from a strategic view, that is from an organisational needs and strategic development perspective, not a technological one. Of course the potential impact of technology is something that determines peoples' requirements. This question seems simple, but it is often neglected by decision makers and ICT curriculum designers. A good answer comes from a thorough understanding of the organisational environment and ICT itself, and is the basis for everything else.

The first question and its answer also reflect and should be improved with the development of the IS discipline, including the evolution of ICT, society and their combination. This implies that many management questions would be solved by the proper use of ICT, and so the importance of IS comes from the ability of ICT to solve management problems, especially some strategic ones. Good solutions come from good combinations of ICT and business requirements. It is this combination, not ICT itself that determines the value of IS. The answer to the first question gives students a general view of ICT in organisations and will guide them to understand what organisations need and what ICT can do for them.

The emphasis of the second question is to customise. This asks of the IS discipline how best to arrange ICT to get a good solution. This needs a good understanding of ICT itself, and of the way ICT is adapted - the same problem in different organisations will need different solutions. On the other hand ICT skills are the basis of customising, which is a long process that needs engineering techniques and related management to ensure quality. All of these are necessary for an IS graduate.

The third question examines IS from a practical business view. As Laudon and Laudon (2001) say: "IS is an organisational and management solution, based on information technology to a challenge posed by the environment." IS will not only support business operations, but may also change business operations and strategy. The process of ICT application is also a process of business reengineering, a process to 
get advantages by the improvement of business and organisation. This question asks researchers to understand society, the economy and the organisation itself. With this knowledge, they can look for problems in current systems and key points to improve organisations by making best use of ICT.

These three questions guide students' understand of IS step by step. The first one shows the real features of IS which serve managers, and belongs to the management field, not to computer science. The last two questions reflect the stages in IS application development and implementation, and the two aspects of IS value in organisations. They show how different people care about different questions and need different knowledge and skills.

\section{Using the Three Questions to Guide Study}

What they should study in university and do after graduation are the first questions students will ask, and the basic questions for the discipline. IS courses are typically designed to include broad business knowledge and skills in ICT so that IS graduates are prepared for the business environment and complex problems of IS development and operation within it. The result is that sometimes students are lost in their study, and in what they should focus on out of so much knowledge. There are not enough ways to help them to integrate what they have learned.

Figure 3 (below) presents a systemic framework (Bacon and Fitzgerald 2001) of the field of IS: its areas of concern and its central theme. It is developed as an integrated framework of five main areas: $I S$ Development, Acquisition and Support, People and Organisations, Information and Communications Technologies, Operations and Network Management, and Information for Knowledge Work, Customer Satisfaction \& Business Performance. The later area is proposed as the central, distinguishing theme for the field.

This framework is comprehensive and has proved meaningful for IS students in understanding what skills they should possess as an IS professional. But it is also too comprehensive to guide students to deal with their study, particularly as different students should have different study aims. Using the three questions we can analyse and summarise the framework, in order to help students to determine their study and development needs.

The central theme of the framework lists several different purposes of information systems, and this is the focus of the first question. IS provides various functions from basic data work to knowledge management, from business performance to customer satisfaction. Every organisation has its own aim. So what the first question means is making sure that an organisation's own aim is at the centre of everything. Information systems thus play a more important role in business life. So IS students should focus on how to combine and merge what they have learned to meet the requirements of business, and become capable of discovering and solving business problems with ICT. At the same time, the importance of the IS discipline also guides students to understand the societal needs and the features of IS.

The second question covers most parts of the figure. Information and Communications Technology is the foundation and material for customising. IS Development, Acquisition and Support gives the reason for customising: it is the direct way of creating systems that satisfy the central theme. In its original form this area was the core of the IS field in the academic environment. While for organisations Operations and Network Management may be the strategic focus, it is a part of customising IS and this area has been relatively neglected. These areas show different aspects of customising and the second question summarises them from a user view. With the help of the second question, the framework assists different people to think about the needs of their own business.

People and Organisation is listed as a major area because it is people in organisations who determine, specify, develop, exploit, support, are empowered by, and rely upon information and information and communication technologies (Bacon and Fitzgerald 2001). For these reasons it seems that this area is a sub-area of IS development. From these lists, Business Strategy and Alignment, Process improvement, Organisation development, Change management, etc just mean that organisations should be adjusted. 


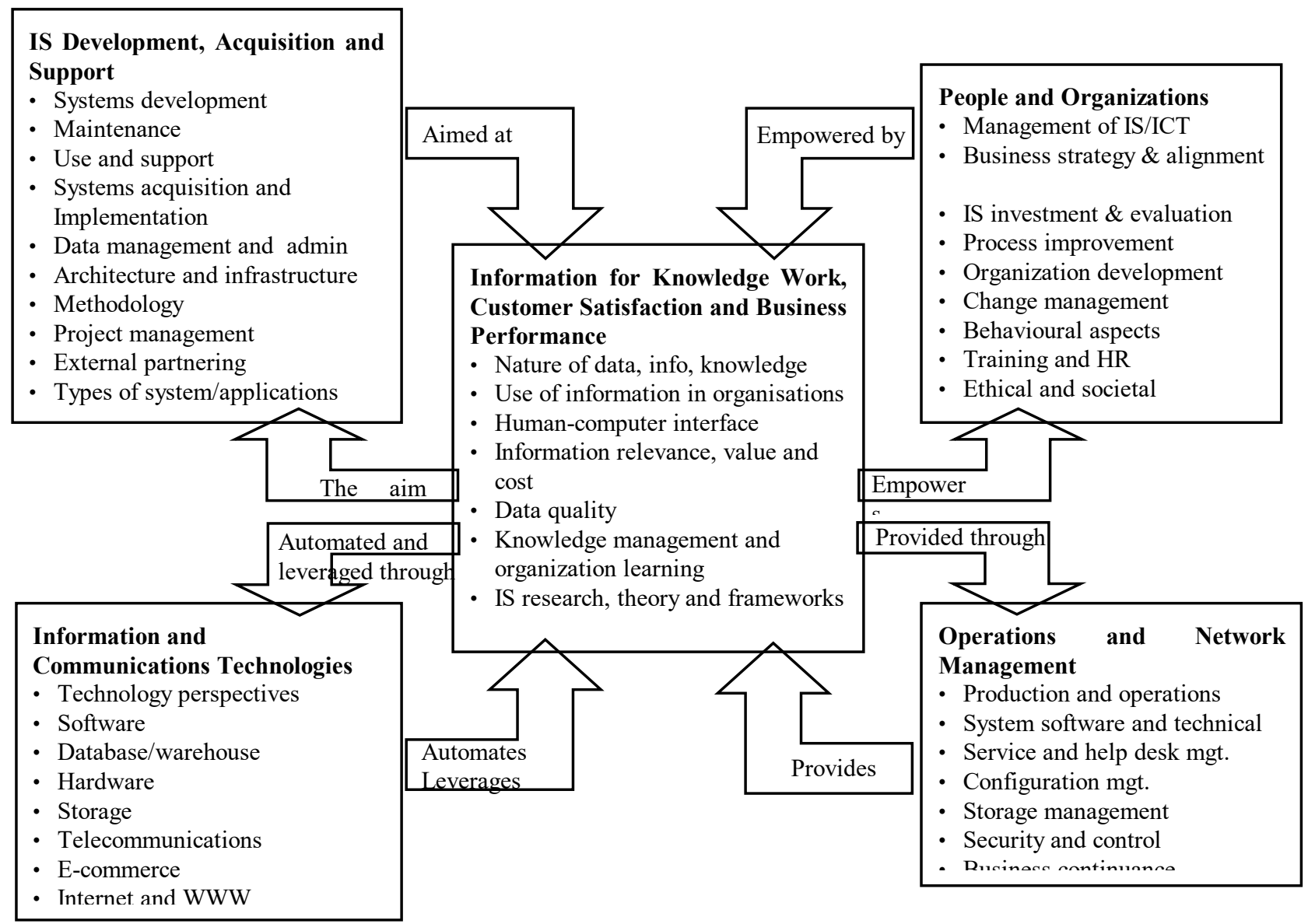

Figure 2: Systemic framework for the field of Information Systems

The third question clearly describes the essence and aim of change, and this inevitably involves many actors (Latour 1996), comprising both humans and non-human artefacts such as computer hardware and software.

\section{Using the Three Questions to Organise Teaching Materials}

Information systems are important for enterprise managers and so, of course, to MBA and MIS graduate students (Tatnall, Davey, Burgess, Davison and Wenn 2002). Courses should cover most topics in the IS discipline to help business manager understand the IS field and guide their future work in IS. The average manager or executive, however, has difficulty in obtaining an integrated and holistic view of IS and this leads to a lack of alignment between IS and the strategic aims of enterprises. Compared with the whole framework of the IS discipline (see figure 3 above) many MBA courses ignore details of ICT itself. Laudon and Laudon's MIS book (2001) is a widely used and comprehensive one, but after reorganising its materials with the 3 questions, it seems much easier for students to obtain an integrated view of the content and to master the essence of the IS field.

The first question can be used to guide students to realise the information systems needs of enterprises and of society, as well as the power and value of IS. How to customise ICT is a big topic requiring much knowledge. With an explanation of the three questions in the first lesson, and guidance on all materials with them, an MIS course seems more interesting and meaningful for MBA students. During subsequent lessons, the three questions are always mentioned and discussed with some cases, which makes the whole course systematic and much easier to master. 


\section{Using the Three Questions and Framework to Guide IS Practice}

After many years of development information systems applications have two distinguishing features: integration and business-intensity. Compared with formerly function-specific systems, organisations need integrated systems to cover all information requirements in the enterprise and more management ideas are involved in development of commercial software. This results in business-intensive applications.

These two features imply that IS has become a big investment, a big value and a big risk. IS investment is a critical decision, and a complicated and difficult task for organisations. Implementation of IS involves every department and every business process in organisations. IS practice involves more business problems and decisions from business managers and executives, all of which need an easy way to classify various problems for explanation to managers and to guide ICT personnel and managers in their work together. The three questions present a common language to guide IS practice.

The following example uses the three questions to guide students in their reading of a book on ERP by Davenport (2000), used it in a subject related to MIS. The book is a comprehensive and general one aimed at business people understanding ERP systems and ICT in business. The first of the three questions suggests that we begin by considering why an ERP system is important to the organisation, and the book handles this in chapters on What are Enterprise Systems and why do they matter? and The promise and perils of Enterprise Systems. These chapters provide an introduction to ERP and their business benefits and describe the roles of ERP in business life. The second question deals with how to customise ERP systems, and several chapters describe this step by step. For an information system such as an ERP system customisation is not development, but a process of implementation. After a general analysis of ERP the book discusses organisations and implementation conditions for ERP systems both from a strategic and an operational viewpoint.

The third question is related to changes in organisations, and the last three chapters answer this in different ways by looking at process, organisation and strategy. There is also discussion of some possible directions within the context of large-scale changes to the business environment within the next few years.

\section{Conclusion}

It is sometimes the case that Information Systems students cannot describe their own discipline. To address this issue, in this paper we proposed three questions: Why are information systems so important for organisations today? How can you customise ICT to meet challenges to organisations? How do you change organisations to get best advantage from ICT? The three questions can be used to help teachers explain the discipline to students, and also to guide students in their learning and mastery of the essence of IS.

The three questions can also form a useful framework for the study of MIS, both for textbook writers and for curriculum designers. They can also be used to good purpose by students in organising their work. Providing answers to the three questions offers students and graduates the possibility of integrating the broad knowledge learned in IS with various management issues in a social context.

Each of the three questions relates to a range of problems and knowledge. Answers to them will cover most aspects of the Information Systems discipline. The questions will clarify different requirements and suggest different knowledge material. For management students and others with different backgrounds, they could be used to clarify their study needs and guide them in the right direction on the long road to IS practice. 


\section{References}

ACS (1997). The Core Body of Knowledge for Information Technology Professionals. http://www.acs.org.au/national/postpaper/bokpt1.htm, September 1997, Australian Computer Society.

Bacon, C. and Fitzgerald, B. (2001). "A Systematic Framework for the Field of Information Systems." The DATABASE for Advances in Information systems. 32(2).

Clements, M. A., Grimison, L. A. and Ellerton, N. F. (1989). Colonialism and School Mathematics in Australia 1788-1988. School Mathematics conference: The Challenge to Change Geelong, Geelong, Australia, Deakin University.

Cougar, J. D., Davis, G. B., Gorgone, J. T., Feinstein, D. L. and Longenecker, H. E. (1995). Information Systems IS'95 DRAFT Report. Model Curriculum and Guidelines for Undergraduate Degree Programs in Information Systems. USA, AIS, ACM, DPMA.

Davenport, T. (2000). Mission Critical: Realizing the Promise of Enterprise Systems. Cambridge, Ma., Harvard Business School Press.

Davis, G. B., Gorgone, J. T., Cougar, J. D., Feinstein, D. L. and Longnecker, H. E. J. (1997). IS '97 Model Curriculum and Guidelines for Undergraduate Degree Programs in Information Systems. USA, Association for Information Technology Professionals.

Elliot, S. (2002). IS: A Discipline in Crisis. Australasian Information Systems Conference (ACIS2002), Melbourne.

Havelock, R. (1971). Planning for Innovation Through Dissemination and Utilization of Knowledge. Ann Arbor, Centre for Research on Utilization of Scientific Knowledge, Institute for Social Research, University of Michigan.

Ingwersen, P. (1996). Information and Information Science in Context. Informing Science: From the Development of Discipline to Social Interaction. Oliasen, J., Erland, M. P. and Wilson, P. Oslo, Scandnavian University Press: 69-111.

Khazanchi, D. and Munkvold, B. (2000). "Is Information Systems A Science? An Inquiry into the Nature of the Information Systems Discipline." The DATABASE for Advances in Information systems. 31(3).

Latour, B. (1996). Aramis or the Love of Technology. Cambridge, Ma, Harvard University Press. Laudon, K. C. and Laudon, J. P. (2001). Management Information Systems. USA, Prentice Hall. Lee, A. S. (2001). "Editorial." MIS Quarterly 25(1).

Longenecker, H. E. J., Feinstein, D. L., Couger, J. D., Davis, G. G. and Gorgone, J. T. (1994). "Information Systems '95: A Summary of the Collaborative IS Curriculum Specification of the Joint DPMA, ACM, AIS Task Force.” Journal of Information Systems Education Winter 1994-95: 174186.

Nordvall, R. C. (1982). The process of change in higher education institutions. Washington DC, American Association for Higher Education.

Nunamaker, J. F. E. (1981). "Educational Programs in Information Systems: a report of the ACM Curriculum Committee on Information Systems." Communications of the ACM 24(3): 124-133.

Sandman, T. E. (1993). "A Framework for Adapting a MS/MIS Curriculum to a Changing Environment." Journal of Computer Information Systems 34(2): 69-73.

Tatnall, A., Davey, B., Burgess, S., Davison, A. and Wenn, A. (2002). Management Information Systems - concepts, issues, tools and applications. Melbourne, Data Publishing. 